Chapman University

Chapman University Digital Commons

Biology, Chemistry, and Environmental Sciences Science and Technology Faculty Articles and Faculty Articles and Research

$2-13-2020$

\title{
The Role of Dislodgement in the Territorial Ecology of the Owl Limpet, Lottia gigantea
}

Ryan T. Kabala

Natalie Swinford

Maria J. Mason

William G. Wright

Follow this and additional works at: https://digitalcommons.chapman.edu/sees_articles

Part of the Biology Commons, Marine Biology Commons, Other Animal Sciences Commons, Population Biology Commons, and the Terrestrial and Aquatic Ecology Commons 


\section{The Role of Dislodgement in the Territorial Ecology of the Owl Limpet, Lottia}

gigantea

\section{Comments}

This is an Accepted Manuscript of an article published in Ethology Ecology \& Evolution in 2020, available online at https://doi.org/10.1080/03949370.2020.1717639. It may differ slightly from the final version of record.

\section{Copyright}

Taylor \& Francis 
1 The role of dislodgment in the territorial ecology of the owl limpet, Lottia gigantea

2

3

RyAn T. KABAlA ${ }^{1,2}$, NATAlie A. SWinforD ${ }^{1,3}$, MARIA J. MASON ${ }^{1,4}$ and William G. Wright ${ }^{1 *}$ ${ }^{1}$ Schmid College of Science and Technology, Chapman University, One University Dr, Orange CA 92866,USA (E-mail: wwright@chapman.edu)

${ }^{2}$ Department of Biological Science, California State University Fullerton, 800 North State College Blvd, Fullerton, CA 92834,USA (E-mail: rkabala@csu.fullerton.edu)

${ }^{3}$ Department of Anthropology, University of California, Davis, One Shields Ave., Davis, CA 95616, USA (E-mail: natalieswinford@gmail.com)

${ }^{4}$ University of Oklahoma, The Children's Hospital, Department of Pediatrics, 1200 Children's Ave. Ste 14402, Oklahoma City, OK 73104,USA (E-mail: mariajmason@gmail.com) *Corresponding author: William G. Wright, Schmid College of Science and Technology, Chapman University, One University Dr, Orange CA 92866, USA

Highlights: Territorial owl limpets have the capacity to completely dislodge competing conspecifics, presumably increasing the adaptive value of this behavior.

Ascertaining the risks and benefits of different behaviors is a central goal of research on territoriality. Although most territorial behavior is ritualized, with concomitant reduced risks for both residents and intruders, this ritualization is generally found to be underpinned by rare, highly consequential, interactions. The agonistic behavior of the intertidal owl limpet, Lottia gigantea, involves defense of a feeding territory, and includes a relatively explosive thrusting response by territory holders against intruding conspecifics. We here ask whether this thrusting 
25 behavior is capable of entirely dislodging intruders from their rocky wave-swept substratum,

26 thereby ridding the resident of future challenges by that intruder. Our field measurements of the

27 strength of territorial thrusts, as well as thrust resistance, indicate that territorial limpets are

28 strong enough to overcome the resistance of small to medium sized $(<40 \mathrm{~mm})$ conspecifics

29 encountered on their territories. Interestingly, at least $44 \%$ of the limpets dislodged from the

30 rock substratum during a retreat or territorial response survived in a new location. Growth of

31 these survivors was at least as rapid as that of undisturbed limpets in the old location.

32 We conclude that shell thrusting during the territorial response of Lottia gigantea can

33 reduce the cost of territorial defense by dislodging smaller conspecifics, thereby eliminating

34 them from all future interactions. Conversely, the risk incurred by these smaller conspecifics

35 while intruding onto territories of larger individuals is likely mitigated by the surprisingly high

36 survival rate, and subsequent normal growth, of dislodged limpets.

38 KEY WORDS: risks, benefits, defense, intrusion, waves, retreat, aggression.

39 Running title: Territorial dislodgement

40 
42 A full understanding of any natural behavior should include knowledge of the costs and

43 benefits of specific behavioral alternatives (Stamps 1994; Hinsch \& Komdeur 2010; Rubenstein

44 \& Alcock 2018). Such knowledge is particularly important for understanding the evolution of

45 agonistic behavioral systems (Adams 2001). Feeding territoriality is a good example of this: for

46 such territoriality to evolve and persist, costs of defending a territory from multiple intruders

47 must be offset by the benefits of that defense (Ewald \& Bransfield 1987; Hinsch et al. 2012;

48 Hinsch \& Komdeur 2017b). If there are too many intruders incurring little risk while stealing

49 food from a territorial resident, territorial behavior becomes too costly, and will not persist. On

50 the other hand, if the risk of death or damage to intruders in the face of the resident's territorial

51 defense is too high, intrusion will become rare or absent (Hinsch \& Komdeur 2010). Thus,

52 questions of the risks and benefits of intruding onto a feeding territory, as well as those of

53 defending one, are key to predicting when territorial behavior is likely to evolve/persist. The

54 present study initiates an investigation of these risks and benefits in the limpet, Lottia gigantea

55 (Mollusca Gastropoda Patellogastropoda).

56 Patellogastropod limpets comprise a speciose monophyletic clade of gastropods that

57 primarily graze the micro-algae that grows on marine near-shore rocky substrates. World-wide,

58 individuals of some 10 species, scattered among ca 214 species of near-shore patellogastropods

59 (Branch 1975a, 1975b, 1976, 1981, Mmonwa et al. 2017; D. Lindberg pers. comm.; pers.

60 comm.), defend small $\left(<3000 \mathrm{~cm}^{2}\right)$ discrete feeding territories from con- and heterospecifics,

61 which intrude in an attempt to feed on the richer algal resources there (Beebe 1942; Galbraith

62 1965; Stimson 1970; Branch 1975a, 1975b, 1976, 1981; Shanks 2002). The only ecological

63 correlate of is that virtually all territorial limpet species live in habitats with relatively high wave 
64 activity. However, many non-territorial limpets inhabit such habitats, diminishing the value of

65 this correlate. In any case, these territorial limpet species present a clear opportunity to test

66 hypotheses about territorial ecology in a lineage entirely separate from the vertebrates and

67 insects that comprise the majority of studies on territoriality. Furthermore, their accessibility

68 and limited territory size make them amenable to experimental manipulation (Stimson 1970,

69 1973; Wright 1982).

70 Among the 26 limpet species found on the west coast of North America (D. Lindberg pers.

71 comm.), only Lottia gigantea shows unequivocal territorial behavior (Stimson, 1970; Wright

72 1982, 1989; Wright \& Shanks 1993), although limited quasi-aggressive behavior around home

73 scars has been reported for L. scabra (Sutherland 1970). Lottia gigantea is a long-lived (Wright

74 1989; Fenberg \& Roy 2012) patellogastropod, whose territorial individuals defend small (400-

$752000 \mathrm{~cm}^{2}$; Stimson 1970) territories from other con- and heterospecific grazers (Stimson 1970,

76 1973; Wright 1982, 1985; Wright \& Shanks 1993; Shanks 2002). A resident protects its feeding

77 territory by pursuing and pushing intruders to the perimeter of its territory (Stimson 1970, 1973;

78 Wright 1982). In the present study, we tested whether this territorial behavior is vigorous

79 enough to break the seal of a conspecific intruder with the rocky substratum, making it

80 vulnerable to being washed off the substratum by a passing wave.

81 Previous investigators of territorial behavior in L. gigantea have observed such

82 dislodgement, but only of "bait limpets", artificially introduced individuals of L. gigantea,

83 previously removed from another area and then placed in the path of a territorial resident

84 (Stimson 1970; Wright 1982). Investigators have generally assumed that naturally intruding

85 conspecifics also risk dislodgement by the bulldozing resident. This assumption is quite

86 significant, because many intertidal ecologists hold that dislodgement necessarily leads to death 
87 (Denny 1985; Boulding \& Van Alstyne 1993; Trussell 1997) as a consequence of predation by

88 mobile (Wells 1980; Pawlik et al. 1986; Silva et al. 2008, 2010) or sessile (Sebens 1981; Ricketts

89 et al. 1992; McQuaid et al. 1999) predators. In any case, the assumption that territorial residents

90 can dislodge intruders has remained untested, because adhesion to the substratum of artificially

91 introduced intruders is severely compromised (Shanks et al. 1986; Smith 1992, 2002; Shanks

92 2002). Thus, such previously removed "bait limpets" placed in front of moving territorial

93 limpets are likely to be much more weakly adhered to the substratum than unmanipulated

94 moving limpets. Furthermore, because natural territorial encounters are relatively rare and

95 limpet behavior is difficult to observe when the tide is in (Stimson 1970; Wright 1982, 1985,

96 1989), direct observations of natural territorial intrusions in the field are few (Wright 1982, 1985,

97 1989), and observation of dislodgement of natural intruders by residents is lacking.

98 Dislodgement of intruders by territorial limpets is thus the focus of the present study,

99 which asks three questions: (1) Which, if any, conspecific intruders onto territories can be

100 dislodged from the substratum by the thrusts of the resident? (2) If these thrusts do dislodge

101 intruders, what are their chances of survival? (3) How does the growth rate of dislodged limpets,

102 subsequent to dislodgement, compare to that of undisturbed conspecifics?

\section{METHODS}

104 Mason et al. (2018) compared the hydrostatic lift force required for a wave to wash off

105 individuals of L. gigantea engaged in different agonistic behaviors to the calculated lift forces of

106 local wave action in order to estimate wash-off risk of behaving limpets. Here, we employed

107 variations of these methods to compare the maximum shear forces exerted by limpets during

108 their territorial response to the ability of intruding limpets to resist such shear forces.

109 Risk of dislodgement 
111 limpets, i.e., limpets $>15 \mathrm{~mm}$ larger than their largest neighbor within $0.5 \mathrm{~m}$. Onto the top of

112 each of these limpets we glued a permanent numbered tag using water-proof two-part epoxy

113 (“Splash Zone”, Z-spar Inc). To enable later measurement of the strength of their territorial

114 thrust (see below), we also glued a screw eye to the posterior part of each limpet's shell (Fig. 1).

115 We measured the longest length of each limpet to the nearest $0.3 \mathrm{~mm}$ using digital calipers. We 116 also identified prospective retreater limpets. A prospective retreater has one or more neighbors

117 (within less than $0.5 \mathrm{~m}$ ), whose shell lengths are at least $15 \mathrm{~mm}$ longer than its own. We tagged, 118 and measured prospective retreaters, as above.

119 Field observations of limpet behavior were conducted June through September 2012, and 120 July 2014-January 2015, near Corona del Mar, California (33.591413ํ, $\left.117.872104^{\circ} \mathrm{W}\right)$, 121 mainly after dark when predicted high-low tidal heights were 0.4-0.6 m above mean lower-low 122 water. We found such high-low tides to be high enough to consistently wet most limpets, and at

123 the same time low enough to allow unobstructed observation of behavior. During these

124 observations, we identified foraging subject limpets by the presence of anterior cephalic tentacles

125 extended beyond their shell (Wright 1982; Mason et al. 2018).

126 Thrust capacity

127 Upon identifying a foraging limpet with a tag and a posterior screw eye, we first induced 128 territorial behavior by contacting the head/tentacles, mantle or foot of a recently removed 129 conspecific "bait" limpet to the cephalic tentacles of the prospective territorial subject (Fig. 1).

130 Once the subject's territorial response was initiated (movement of more than one shell length in 131 less than $90 \mathrm{sec}$ in pursuit of the bait limpet), we connected a line from the attached screw-eye on 132 the subject limpet to a spring scale with a maximum reading pointer, all the while maintaining 
133 contact of the bait limpet to the cephalic tentacles of the subject. Once the line was taut, the

134 spring scale was held steady to measure the maximum force exerted by the subject as it moved in

135 pursuit of the bait limpet (see Fig. 1).

136 Resistance to thrust force

137 To measure resistance to thrust force, we first placed a bait limpet in front of a limpet foraging

138 near a larger conspecific (Fig. 2). As the subject limpet turned away from the bait limpet, we

139 maintained contact of the soft parts of the bait and subject limpets (Fig. 2, top panels), first

140 touching the bait limpet to the tentacles of the subject limpet, and, upon the subject turning

141 farther than $90^{\circ}$ from its initial orientation, shifting the bait-limpet contact to more posterior parts

142 of the subject's mantle and foot. Limpets were defined as "retreating" if they moved more than

$14390^{\circ}$ away from the point of contact within $90 \mathrm{sec}$. Once a subject had retreated $1-3$ shell lengths

144 we measured its resistance to shear force (Fig. 2, top panels) by dragging an empty limpet shell

145 (ca $55 \mathrm{~mm}$ ), with a line attached to a spring scale with a maximum reading pointer, up against

146 the retreating subject limpet. We continually held the anterior end of the empty limpet shell

147 lightly against the substratum, while pulling the spring scale-line-shell across the subject limpet

148 with a constant velocity approximating that of moving territorial limpets $\left(5-20 \mathrm{~cm} \cdot \mathrm{min}^{-1}\right.$, Wright

149 1982; Mason et al. 2018) until the subject was dislodged (Fig. 2, upper right panel). Note that

150 this meant that the actual force applied by the dragged shell across the subject necessarily

151 increased, sometimes substantially, over the 1-2 sec of contact with the empty shell, until the

152 subject was dislodged, at which point the maximum reading pointer would register this "force to

153 dislodge." In this way, we measured and recorded the thrust force required by this model of a

154 territorial resident to dislodge an actively retreating intruder. Some subject limpets did not

155 retreat in response to intraspecific contact, but, instead, simply continued foraging. We tested 
156 the dislodgement force of these limpets as well (Fig. 2, lower panels). Many of the limpets on

157 which thrust resistance was measured were not previously tagged. Such limpets were retained

158 after dislodgement to allow measurement of their shell length to the nearest $0.3 \mathrm{~mm}$ with digital

159 calipers.

160 Effect of dislodgement on mortality and growth rate

161 Some of the dislodged limpets had been previously tagged and measured. These limpets were 162 not retained when they were dislodged, but instead allowed to be taken by the waves. On four

163 separate occasions, we performed multiple (8-20) such dislodgements on different tagged

164 limpets. Two weeks after each of those occasions (30 July, 24 October, 22 and 23 December

$1652014 ; 21$ January 2015) we returned to the same intertidal region to search for survivors among

166 these dislodged limpets.

167 On the first of those occasions (30 July 2015), we remeasured shell length of survivors,

168 as well as the shell length of many additional limpets that had been tagged, but not previously

169 dislodged (most were not moving during the high-low tide 2 weeks before). This "undislodged"

170 group comprised a control against which the growth of the dislodged limpets could be compared.

171 We then returned to the intertidal 5.3 months later (7 January 2015) to measure shell length, and

172 thereby growth rate of both dislodged (seven of the nine survivors still had their tags) and

173 untouched control limpets. Note that limpet growth in shell length represents the net sum of

174 shell added and shell eroded (Wright 1985; Shanks \& Wright 1986) and can thus be negative,

175 indicating that the limpet has accreted less shell material than has been eroded.

176 All statistical tests of significance (t-tests, correlation, regression slopes, analysis of

177 covariance) are 2-tailed. We report averages \pm standard error of means. We plot scattergrams, 178 and report Pearson's $\mathrm{R}^{2}$ (and two-tailed $P$-value) for generated Thrust Force vs Shell Length. To 
179 understand the functional relationships of Thrust resistance to combinations of Shell Length and

180 Behavior and their interaction, we performed a full interaction general linear model (lm: Thrust

181 Resistance $\sim$ Shell Length + Behavior + Shell Length:Behavior; R-project) on the data.

\section{RESULTS}

\section{Thrust capacity}

184 We found wide variation in the capacity of territorial limpets to generate thrust force (1.8-6.7 N, 185 mean $=4.6 \pm 0.3$ ), and much of this variation was correlated with shell length (Fig. $3 ; \mathrm{R}^{2}=0.43$, $186 \mathrm{n}=27, P=0.0002)$.

187 Resistance to thrust

188 The full linear model of thrust resistance as a function of shell length, behavior, and their 189 interaction $\left(\mathrm{F}_{3,30}=64, P<0.0001\right)$, revealed significant main effects of shell length $(P<0.0001)$ 190 and behavior $(P=0.002)$ on thrust resistance (Fig. 4): thrust resistance was positively correlated 191 with shell length for both retreaters (Fig. 4, gray symbols, $\mathrm{R}^{2}=0.36, \mathrm{~N}=26, P=0.001$ ) and

192 continued foragers (Fig. 4, open symbols, $\mathrm{R}^{2}=0.66, \mathrm{~N}=8, P=0.014$ ), and limpets that

193 continued foraging resisted thrust more effectively (6.6-61.2 N, mean $=35.3 \pm 7.2 \mathrm{~N}$, Fig. 4,

194 white symbols) than did limpets that retreated $(0.2-16 \mathrm{~N}$, mean $=4.7 \mathrm{~N} \pm 0.8$, Fig. 4, gray

195 symbols), and in addition, there was a highly significant interaction between shell length and 196 behavior in predicting thrust resistance $(P<0.0001)$, reflecting the clear pattern that thrust 197 resistance ascended much more steeply with increased shell length $\left(\right.$ slope $\left.=1.8 \mathrm{~N} \cdot \mathrm{mm}^{-1}\right)$ in 198 limpets that continued foraging than it did in limpets that retreated (slope $\left.=0.27 \mathrm{~N} \cdot \mathrm{mm}^{-1}\right)$.

\section{Thrust capacity vs resistance}

201 In Fig. 5, results from Fig. 3 are plotted with those from Fig. 4 to visualize which limpets are 
202 vulnerable to being dislodged by territorial limpets. Also shown is the window of vulnerability

203 (grey area); its height represents the maximum thrust-force $(6.7 \mathrm{~N})$, observed from a territorial

204 limpet. Thrust resistance of retreating limpets was dangerously weak: 20 of 26 limpets (77\%)

205 were dislodged by less than $6.7 \mathrm{~N}$, thus putting them in the window of vulnerability. By contrast

206 the resistance of only one of eight limpets (13\%) that continued slow foraging in response to the

207 bait limpet was vulnerable to dislodgement. These data indicate that limpets that continued slow

208 foraging in response to intraspecific contact were unlikely to be dislodged by a thrusting

209 territorial limpet, whereas the reduced tenacity of those that chose to retreat, especially those

210 smaller than $40 \mathrm{~mm}$, made them more vulnerable to such thrusts.

211 Survival/growth of dislodged limpets

212 On four different dates, we baited tagged subject limpets into agonistic (retreat or territorial)

213 behavior, and upon their beginning rapid agonistic behavior, dislodged them (see Methods). The

214 survivorship of limpets dislodged during these semi-natural behavioral interactions was

215 surprisingly high (average of each of the four dates: $0.446 \pm 0.068$, Fig. 6). We did not estimate

216 survival of limpets that were dislodged during continued foraging because their likelihood of

217 dislodgement by a territorial limpet was so low (see previous paragraph).

218 Growth of limpets following dislodgement during "chase behavior" (territorial limpets

219 combined with retreat limpets, Fig. 7, $\mathrm{N}=7$ ) was similar to that of untouched control limpets

220 over the same period $(\mathrm{N}=54)$, although the growth of the two limpets dislodged after retreat

221 behavior trended higher than expected.

DISCUSSION

223 This field comparison of potency of territorial defense to the resistance of intruders to

224 that defense is the first evidence among territorial limpets that their territorial thrusting can 
225 dislodge and thereby eliminate small intruders from future competitive interactions. To the

226 extent that residents have opportunities to successfully deploy this behavior, it can significantly

227 reduce their future competitive costs: Each intruder removed in this way would reduce the

228 number of subsequent territorial responses required, thereby reducing energy expended on

229 territory defense. It would also reduce the risk of wash-off by waves during subsequent

230 territorial chase of the same intruder (Mason et al. 2018). Finally, it would also increase

231 availability of future algal food, which would otherwise be exploited by the persistent intruder

232 (Shanks 2002). Such an effective weapon against the efficient exploitation of territorial gardens

233 by small intruding limpets (Stimson 1970; Shanks 2002) contributes, perhaps critically, to the

234 economics of territoriality in this limpet species. If $L$. gigantea did not have this dislodging

235 territorial behavior, but could instead only manage slow, steady displacement of intruders to the

236 territory perimeter, displaced intruders would likely re-invade, incurring additional costs for the

237 resident that might well outweigh the benefits of territorial behavior.

238 Given this measured danger level of a resident's thrusting territorial response, it is

239 perhaps surprising that small conspecifics so readily intrude onto the territories of larger limpets

240 (Stimson 1970; Wright 1982, 1985, 1989; Wright \& Shanks 1984; Shanks 2002; Schroeder

241 2011). Lottia gigantea is a long-lived species (9-8 years; Wright 1989; Fenberg \& Roy 2012),

242 and compounding risky behavior in the first few years of life by daily exposure to a mortal threat

243 seems counter-intuitive. Previous studies explicitly (Boulding \& Van Alstyne 1993; Denny 1995;

244 Trussell 1997) or implicitly (Denny 1985, 1995; Denny \& Blanchette 2000; Gaylord et al. 2003)

245 assumed dislodgement to be tantamount to death, although Miller et al. (2007) demonstrated

246 high survival of littorine snails after wash off. Our measurements of relatively high survival and

247 no reduction in growth of intruders following dislodgement during their active responses to 
248 intraspecific contact suggest that dislodgement is not nearly as drastic of a life-history crisis as

249 previously assumed. Our estimate of survival after dislodgement in the course of a retreat or

250 territorial response (44\%) is likely an underestimate, since it is based on finding tagged limpets

251 in a large area 2 weeks after dislodgement. These survival and growth data from dislodged

252 limpets shift our understanding of the ecological role of dislodgement of small limpets from a

253 major life-history crisis to a risky inconvenience, and thereby help explain the persistence of

254 intrusion behavior of small limpets onto well-defended territories. This, combined with the

255 ability of small limpets to dodge territorials (Wright 1982) and the demonstrated rich resources

256 to be had on a resident's territory (Shanks 2002), likely contributes to making territorial intrusion

257 a consistently adaptive strategy.

258 Previous research by one of us (W.G. Wright) and colleagues (Shanks et al. 1986; Wright

$259 \&$ Shanks 1995) has documented limpets actively releasing their grip on a substratum that is

260 rolling around in the sea. This release seems at first glance to further belie the contention that

261 dislodgement is very dangerous; however the realization that such rolling substratum is

262 comprised nearly exclusively of dislodged mussels to which limpets are attached, led us to

263 propose that this "bail-out" behaviour reduces the chances that a limpet will be swallowed along

264 with its mussel substratum by an anemone, a common fate of dislodged mussels (Sebens 1981).

265 Dislodged limpets regain their footing orders of magnitude more quickly than do mussels large

266 enough to host epifaunal limpets (Shanks et al. 1986; Wright \& Shanks 1995). Thus, bail out

267 from, not adhesion to, a rolling mussel is likely the safer of these two very dangerous situations.

268 Related to the question of the adaptive value of intrusion is an unknown, but potentially

269 significant, contribution of intrusion directly to reproductive success. In particular, the

270 protandric hermaphroditism of L. gigantea (Lindberg \& Wright 1985; Wright 1989), combined 
271 with the observation (Wright 1989$)$ that only $6 \%(\mathrm{~N}=64)$ of evading limpets were females,

272 means that small intruding limpets are nearly exclusively male. This raises the possibility that

273 one function of the intrusion of small limpets that respond with retreat behavior is to be near the

274 spawn of the resident, which has a good chance $(52 \%, \mathrm{~N}=71$, Wright 1989) of being female.

275 This proximity is very likely to give such an intruding male a competitive fertilization advantage

276 over less bold male intruders. Inasmuch as spawning occurs over no more than a few days every

277 winter (based on suddenly depleted gonad indices, Daly 1975), and has yet to be directly

278 observed, such a scenario will be difficult to illuminate with field observations, and must remain

279 a distant possibility at best.

280 It is worthy of note that the surprisingly benign prospects for the dislodged intruder are

281 unlikely to diminish the adaptive advantage to the resident of its dislodging thrust behavior. This

282 is because reattachment of dislodged limpets almost always occurs several to many meters away

283 from the site of dislodgement, making future exploitation of the original territory by the same

284 intruder quite unlikely. Thus, the resident will likely reduce its local conspecific competition

285 with this thrust behavior.

286 The above considerations paint a picture of a dynamic system of two dueling adaptive

287 behaviors: (1) explosive territorial defense capable of removing a small intruder from any future

288 intrusions, and (2) persistent intrusions by small limpets onto territories to forage on the rich

289 algal resources and dodge the territorial efforts of the resident until luck runs out and they are

290 dislodged, at which time they have a fair chance of surviving and growing in a different location.

291 An alternative, not mutually exclusive, interpretation of the strong territorial response

292 shown by L. gigantea residents, is that its function is to train or "punish" intruders (Stamps 1994;

293 Stamps \& Krishnan 1999; Hinsch \& Komdeur 2017a). Indeed, Wright and Shanks (1993) 
294 demonstrated that agonistic experience of territorial defeats increases the subsequent likelihood

295 that L. gigantea foragers engage in retreat behavior in response to conspecific contact. Wright

296 and Shanks (1993) did not vary the intensity of defeats, e.g., the force of the pushing during

297 training. A reasonable prediction is that more forceful pushing would make intruders more likely

298 to retreat in response to subsequent contact than would weaker pushing; and perhaps decrease the

299 frequency of their intrusions.

300 Although we have not directly tested the resistance of other co-occurring limpet species,

301 such heterospecific limpets $(5-30 \mathrm{~mm})$ can be found on territories of L. gigantea, where they

302 show well-developed retreat behavior in response to limpet contact (W.G. Wright, pers.

303 observation). These limpets are all as small or smaller than retreating L. gigantea, and are thus

304 likely at risk for dislodgement.

305 The fact that $L$. gigantea is most commonly found on vertical habitats with high wave 306 energy (Abbot 1956; Ricketts et al. 1992; Denny \& Blanchette 2000) is likely to amplify the 307 effectiveness of this territorial thrust behavior. Breaking the seal of an intruder's foot with the 308 substratum does the resident little good if the encounter occurs on a horizontal substrate in calm

309 seas (see online video), thus giving the intruder time to re-adhere to the substratum as it is

310 shoved to the edge of the territory.

311 This consideration of the distribution of territoriality supports the idea that wave wash 312 may amplify the effectiveness of the territorial response. The well-studied risk of dislodgement

313 by waves in Lottia gigantea (Denny 1995; Denny \& Blanchette 2000; Mason et al. 2018) is quite

314 likely to interact, perhaps critically, with the ability of territorial residents to rid themselves of

315 exploitative intruders. In particular, removal of intruders from the substratum generally requires

316 both dislodgement by the territorial thrusting, as well as wash-off due to a breaking wave. Thus, 
317 the interaction of territorial behavior with ocean waves may be key. Because we can only

318 observe staged interactions in relatively benign conditions, we do not know if territorial behavior

319 of residents, or retreat behavior of intruders, is different in rougher seas. However, we do know

320 that limpets are loath to move during peak tides when wave heights are above $1.5 \mathrm{~m}$ (Wright $\&$

321 Nybakken 2007).

322 Adaptive considerations suggest that the evolution of a feeding territory requires that

323 territory defense be sufficiently profitable. If the behavior of the territorial resident cannot

324 sufficiently reduce the cost incurred by intruding limpets, territoriality will not persist (Hinsch \&

325 Komdeur 2010). We suggest that the possibility, explicitly identified here, that an intruder that is

326 removed, not just to the perimeter of the territory, but from the entire rocky substratum, can

327 increase the benefit of the resident's territorial behavior by eliminating small intruders from

328 future competitive interactions, thereby increasing future algal food that would be otherwise be

329 exploited by such intruders (Shanks 2002). This suggests that the evolution of the relatively

330 complex thrust-and-follow behavior, which not only enables displacement, but also dislodgement

331 of intruders, may be a necessary requirement for the evolution and persistence of territorial

332 behavior.

333 Conversely, as potentially dangerous as this thrust response is from the perspective of

334 small intruders, its realized ecological effect on them is reduced by their effective retreat

335 behavior, which has significantly shorter latency that the territorial response of residents (Wright

336 1982). This difference in response time results in the observation that most of the directly

337 observed natural contacts between small intruders and residents end with the intruder retreating

338 before the resident responds (Wright 1982). Nevertheless, the explosive thrusting behavior so

339 commonly observed in staged encounters has also been observed in several natural encounters 
340 (Wright 1982; W.G. Wright pers. observation); thus, its use is unlikely to be an artifact of the

341 baiting method used to elicit territorial behavior.

342 Owl limpets also respond with similar territorial thrusting to intrusions by at least two

343 different co-occurring limpet species (primarily Lottia digitalis and L. scabra) placed in front of

344 moving territorial residents (Stimson 1970). Although we have observed retreat behavior by

345 both species from limpet contact while foraging on L. gigantea territories, we do not yet know

346 the latency or speed of these behaviors. Thus, the dangerous dislodging component of the

347 territorial thrust response may be also, or even primarily, useful against hetero-specific intruders,

348 whose exploitation of territories would otherwise take a competitive toll on territorial residents

349 (Stimson 1973).

350 To conclude, these measurements and observations suggest that the evolutionary

351 persistence of the territorial ecology of L. gigantea is attributable to two different somewhat

352 surprising characteristics: (1) Exuberant territorial response: rapid pursuit, agile directional

353 tracking, and thrust behavior, give a territorial resident the potential to dislodge small intruders,

354 permanently removing them from further competitive interactions with the resident. (2) Low-cost

355 intrusion: exploitation of this apparently dangerous territory remains adaptive, partly because

356 such intruders are quicker to respond (Wright 1982), but also because, if dislodged, they stand a

357 reasonable chance of surviving and continuing to grow in a new location. Thus, we suggest that

358 the "win-win" ethological setting manifested by these two characteristics together contribute to

359 the robust territorial ecology of L. gigantea.

ACKNOWLEDGEMENTS

362 We would like to acknowledge the help of numerous Chapman University 'limpet wrasslers' 
363 who assisted in collecting the behavioral data for this study. John Berriman, Michelle Gibbons,

364 Nelson Gould, Bishoi Nassef, and Tyler ten Broek, braved the waves on multiple occasions. We 365 also thank David please, insert full forename as for others Lindberg and Walter Piper for critical 366 reads of the ms.

\section{REFERENCES}

369 Abbott DP. 1956. Water circulation in the mantle cavity of the owl limpet Lottia gigantea Gray.

$370 \quad$ Nautilus. 69:79-87.

371 Adams ES. 2001. Approaches to the study of territory size and shape. Ann Rev Ecol Syst.

$372 \quad 32: 277-303$.

373 Beebe W. 1942. Book of bays. Chicago (IL): University of Chicago.

374 Boulding, EG, Van Alstyne KL. 1993. Mechanisms of differential survival and growth of 2

375 species of Littorina on wave-exposed and on protected shores. J Exp Mar Biol Ecol 169:139376166.

377 Branch GM. 1975a. Intraspecific competition in Patella cochlear Born. J Anim Ecol 44:263-281

378 Branch GM. 1975b. Mechanisms reducing intraspecific competition in Patella spp: Migration, 379 differentiation, and territorial behavior. J Anim Ecol 44:575-600.

380 Branch GM. 1976. Interspecific competition experienced by South-African Patella species J 381 Anim Ecol 45:507-529.

382 Branch, GM. 1981. The biology of limpets: physical factors, energy flow, and ecological 383 interactions. Aberdeen. Aberdeen University Press.

384 Daly G. 1975. Growth and reproduction in the marine limpet Lottia gigantea (Gray)

385 (Acmaeidae) [Masters Thesis]. San Diego (CA): San Diego State University. 
Denny M. 1985. Wave forces on intertidal organisms: A case study. Limnol Oceanogr 30:1171-

3871187.

388 Denny M. 1995. Predicting physical disturbance: Mechanistic approaches to the study of 389 survivorship on wave-swept shores. Ecol Monogr 65:371-418.

390 Denny MW, Blanchette CA. 2000. Hydrodynamics, shell shape, behavior and survivorship in the 391 owl limpet Lottia gigantea. J Exp Biol 203:2623-2639.

392 Ewald PW, Bransfield RJ. 1987. Territory quality and territorial behavior in two sympatric 393 species of hummingbirds. Behav Ecol Sociobiol 20:285-293.

394 Fenberg PB, Roy K. 2012. Anthropogenic harvesting pressure and changes in life history:

395 Insights from a rocky intertidal limpet. Am Nat 180:200-210.

396 Galbraith RT. 1965. Homing behavior in the limpets Acmaea digitalis and Lottia gigantea. Am 397 Midl Nat 74:245-246.

398 Gaylord B, Denny MW, Koehl MAR. 2003. Modulation of wave forces on kelp canopies by 399 alongshore currents. Limnol and Oceanogr 48:860-871.

400 Hinsch M, Komdeur J. 2010. Defence, intrusion and the evolutionary stability of territoriality. J 401 theor Biol 266:606-613.

402 Hinsch M, Komdeur J. 2017a. Punish the thief - coevolution of defense and cautiousness 403 stabilizes ownership. Behav Ecol Sociobiol 71:102.

404 Hinsch M, Komdeur J. 2017b. What do territory owners defend against? Proc R Soc B $405 \quad 284: 20162356$.

406 Hinsch M, Pen I, Komdeur J. 2012. Evolution of defense against depletion of local food 407 resources in a mechanistic foraging model. Behav Ecol 24:245-252. 
408 Lindberg, D. R., Wright, W. G. 1985. Patterns of sex change of the protandric patellacean limpet

409 Lottia gigantea (Mollusca, Gastropoda). Veliger 27: 261-265.

410 Mason MJ, Zachary VA, Berriman J, Mason AB, Rakovski CS, Wright WG. 2018. Reduced

411 tenacity during "high-speed" territorial encounters in the intertidal owl limpet, Lottia gigantea:

412 Agonistic escalation increases risk of wash-off. J Exp Mar Biol Ecol 509:71-81.

413 McQuaid CR, Cretchley R, Rayner JL. 1999. Chemical defence of the intertidal pulmonate

414 limpet Siphonaria capensis (Quoy \& Gaimard) against natural predators. J Exp Mar Biol Ecol

$415 \quad 237: 141-154$.

416 Miller LP, O'Donnell MJ, Mach KJ. 2007. Dislodged but not dead: survivorship of a high

417 intertidal snail following wave dislodgement. J Mar Biolog Ass UK 87:735-739.

418 Mmonwa, K. L., Teske, P. R., McQuaid, C. D., Barker, N. P. 2017. Evolution of foraging

419 behaviour: Deep intra-generic genetic divergence between territorial and non-territorial southern

420 African patellid limpets. Mol Phylogen and Evol 117: 95-101.

421 Pawlik JR, Albizati KF, Faulkner DJ. 1986. Evidence of a defensive role for limatulone, a novel

422 triterpene from the intertidal limpet Collisella limatula. Mar Ecol Progr Ser 30: 251-260.

423 Ricketts EF, Calvin J, Hedgpeth JW. 1992. Between Pacific tides, $5^{\text {th }}$ ed. Palo Alto, Stanford

424 University Press.

425 Rubenstein DR, Alcock J. 2018. Animal behavior. Oxford. Sinauer.

426 Schroeder SL. 2011. The behavioral ecology and territoriality of the owl limpet, Lottia gigantea,

427 Masters Thesis. University of Oregon.

428 Sebens, K. P. 1981. The allometry of feeding, energetics, and body size in three sea anemone

429 species. Biol Bull. 161(1): 152-171. 
430 Shanks AL., Wright W. G. 1986 Adding teeth to wave action: the destructive effects of wave-

431 borne rocks on intertidal organisms. Oecologia 1986: 69(3):420-8.

432 Shanks AL, Wright WG, Maltz, G. 1986. What triggers the "bail out" behaviour in the limpet

433 Lottia gigantea?. Mar Behav Phys 12: 71-79.

434 Shanks AL. 2002. Previous agonistic experience determines both foraging behavior and

435 territoriality in the limpet Lottia gigantea (Sowerby). Behav Ecol 13:467-471.

436 Silva ACF, Hawkins SJ, Boaventura DM, Thompson RC. 2008. Predation by small mobile

437 aquatic predators regulates populations of the intertidal limpet Patella vulgata (L.). J Exp Mar

438 Biol Ecol 367:259-265.

439 Silva AS, Hawkins SJ, Clarke D. Boaventura DM, Thompson RC. 2010. Preferential feeding by

440 the crab Necora puber on differing sizes of the intertidal limpet Patella vulgata. Mar Ecol Progr

441 Ser 416:179-188.

442 Smith AM, 1992. Alternation between attachment mechanisms by limpets in the field. J Exp

443 Mar Biol Ecol 160:205-220.

444 Smith AM. 2002. The structure and function of adhesive gels from invertebrates. Integr Comp

445 Biol 42:1164-1171.

446 Stamps JA. 1994. Territorial behavior: testing the assumptions. Adv Stud Behav 23(173):232.

447 Stamps JA, Krishnan V.V. 1999. A learning-based model of territory establishment. Quart Rev $448 \quad$ Biol 74(3):291-318.

449 Stimson J. 1970. Territorial behavior of the owl limpet, Lottia gigantea. Ecol 51:113-118.

450 Stimson J. 1973. Role of territory in the ecology of the intertidal limpet Lottia gigantea (Gray).

451 Ecol 54:1020-1030. 
452 Sutherland JP. 1970. Dynamics of high and low populations of the limpet, Acmaea scabra

453 (Gould). Ecol Monogr 40:169-188.

454 Trussell GC. 1997. Phenotypic selection in an intertidal snail: Effects of a catastrophic storm.

455 Mar Ecol Progr Ser 151:73-79.

456 Wells, R. A. 1980. Activity pattern as a mechanism of predator avoidance in two species of

457 acmaeid limpet. J Exp Mar Biol Ecol 48:151-168.

458 Wright, W. G. 1982. Ritualized behavior in a territorial limpet. J Exp Mar Biol Ecol 60:245-251.

459 Wright WG. 1985. The behavioral ecology of the limpet Lottia gigantea: interaction between

460 territoriality, demography, and protandric hermaphroditism. Dissertation, University of

461 California San Diego, San Diego.

462 Wright WG. 1989. Intraspecific density mediates sex change in the territorial patellacean limpet, 463 Lottia gigantea. Mar Biol 100:353-364.

464 Wright WG, Nybakken JW. 2007. Effect of wave action on movement in the owl limpet, Lottia 465 gigantea, in Santa Cruz, California. Bull Mar Sci 81:235-244.

466 Wright WG, Shanks AL. 1984. Fight or flee in a territorial limpet - Substratum cues and 467 previous experience. Am Zool 24:A101-A101.

468 Wright WG, Shanks AL. 1993. Previous experience determines territorial behavior in an 469 archaeogastropod limpet. J Exp Mar Biol Ecol 166:217-229.

470 Wright, W. G. and A. L. Shanks. 1995. Interspecific association between bail-out behavior and 471 habitat is geographically and phylogenetically widespread. J Exp Mar Biol Ecol 188: 133-143. 472 473 


\section{Figures:}

475

\section{Measuring thrust force}
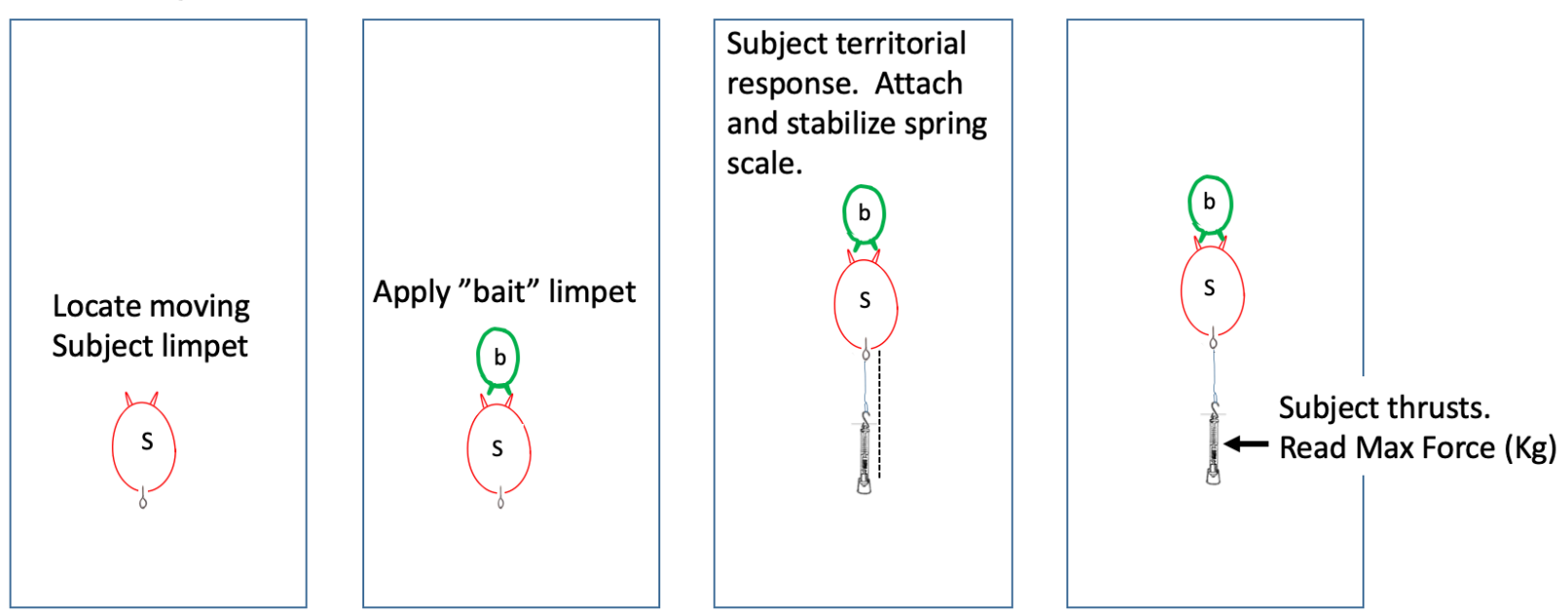

476

477 Fig.1. - Measurement of maximum thrust in territorial limpet. Limpet with ring attached to

478 posterior shell is "baited" into a territorial response. A light line is attached to the ring, and to a

479 spring scale with a maximum reading pointer. The spring scale is stabilized while the line comes

480 taut behind territorial limpet. Maximum thrust force is measured.

481

482

483 
Measuring thrust-force resistance.
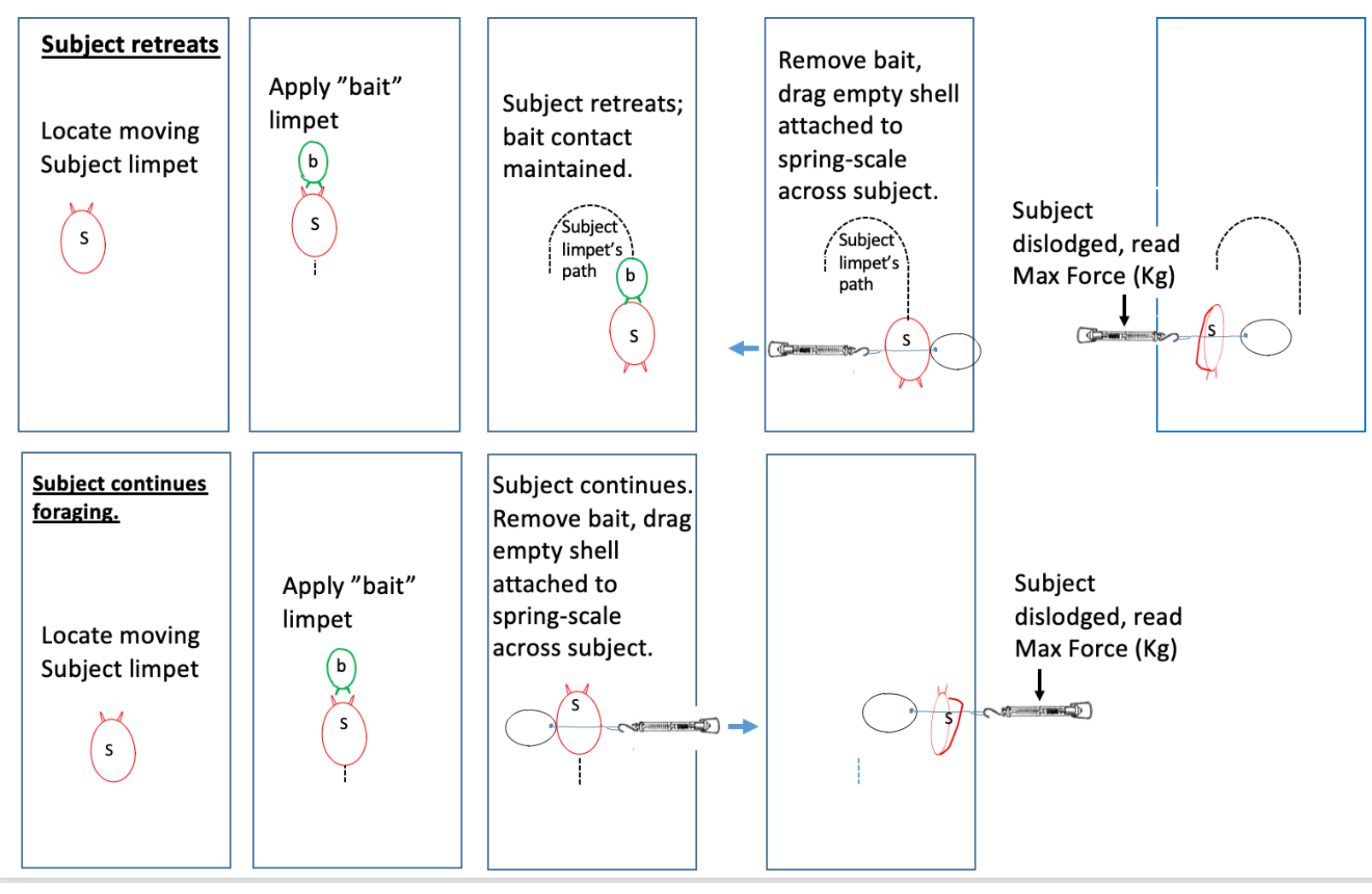

486 Fig. 2. - Measurement of resistance to thrust force in chasing limpets. Subject limpets (red) are

487 "baited" (using a conspecific limpet (green) removed from a different area) into either retreat

488 (above) or territorial (below) behavior. Once a behavioral response is established; either retreat

489 (upper panel), territorial (lower panel), or no response (not shown); an empty shell (no shading)

490 attached to a line and spring scale with maximum pointer is slowly dragged against the limpet

491 until the subject limpet's seal with the substratum is broken. The maximum force exerted until

492 dislodgement is recorded. 


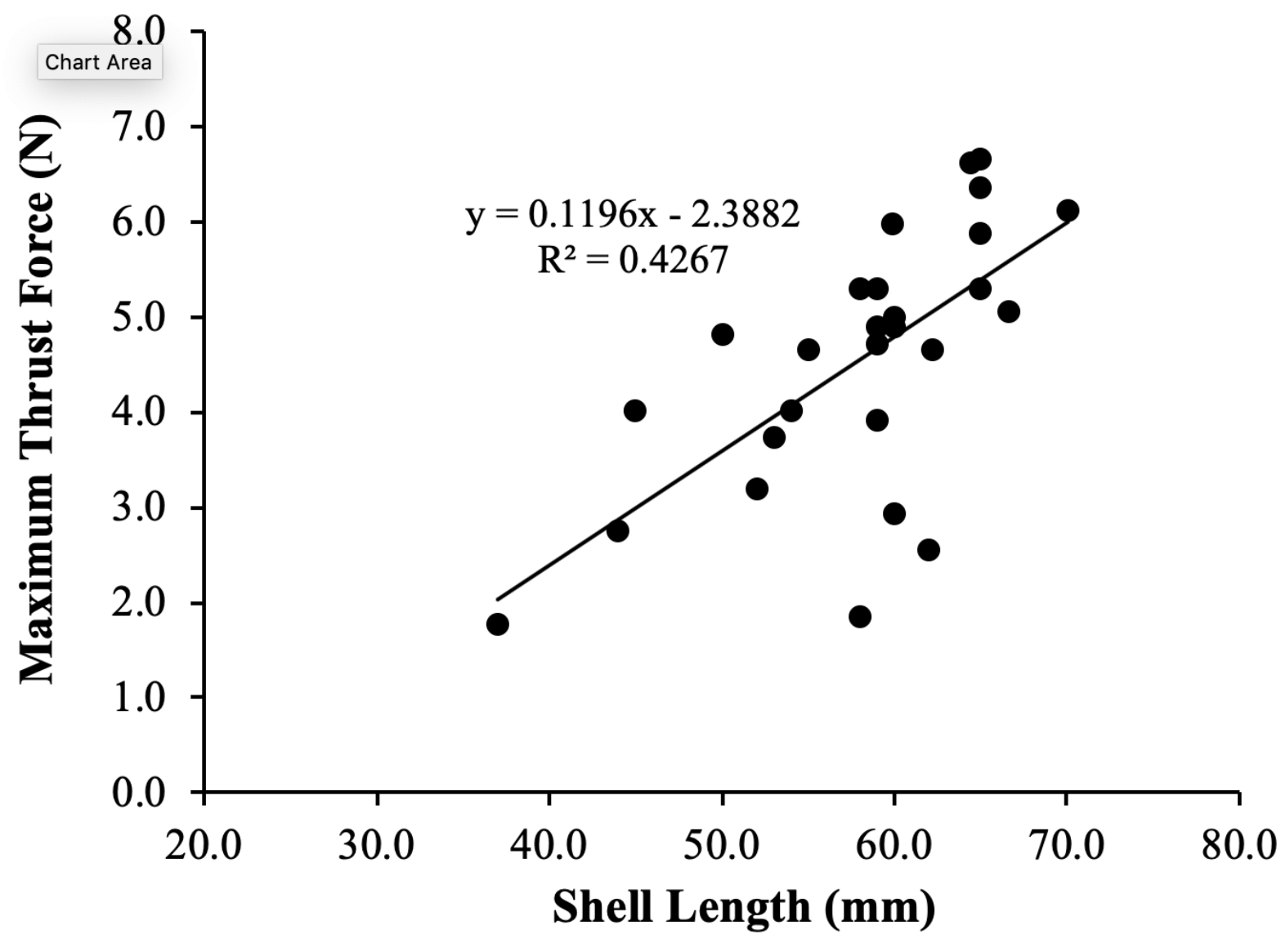

501 Fig. 3. - Thrust force is significantly correlated with shell length. Maximum thrust force

502 produced in territorial limpets (Fig. 1) in response to an introduced bait limpet is shown as

503 function of shell length $\left(\mathrm{R}^{2}=0.43, \mathrm{n}=27, P=0.0002\right)$.

504 


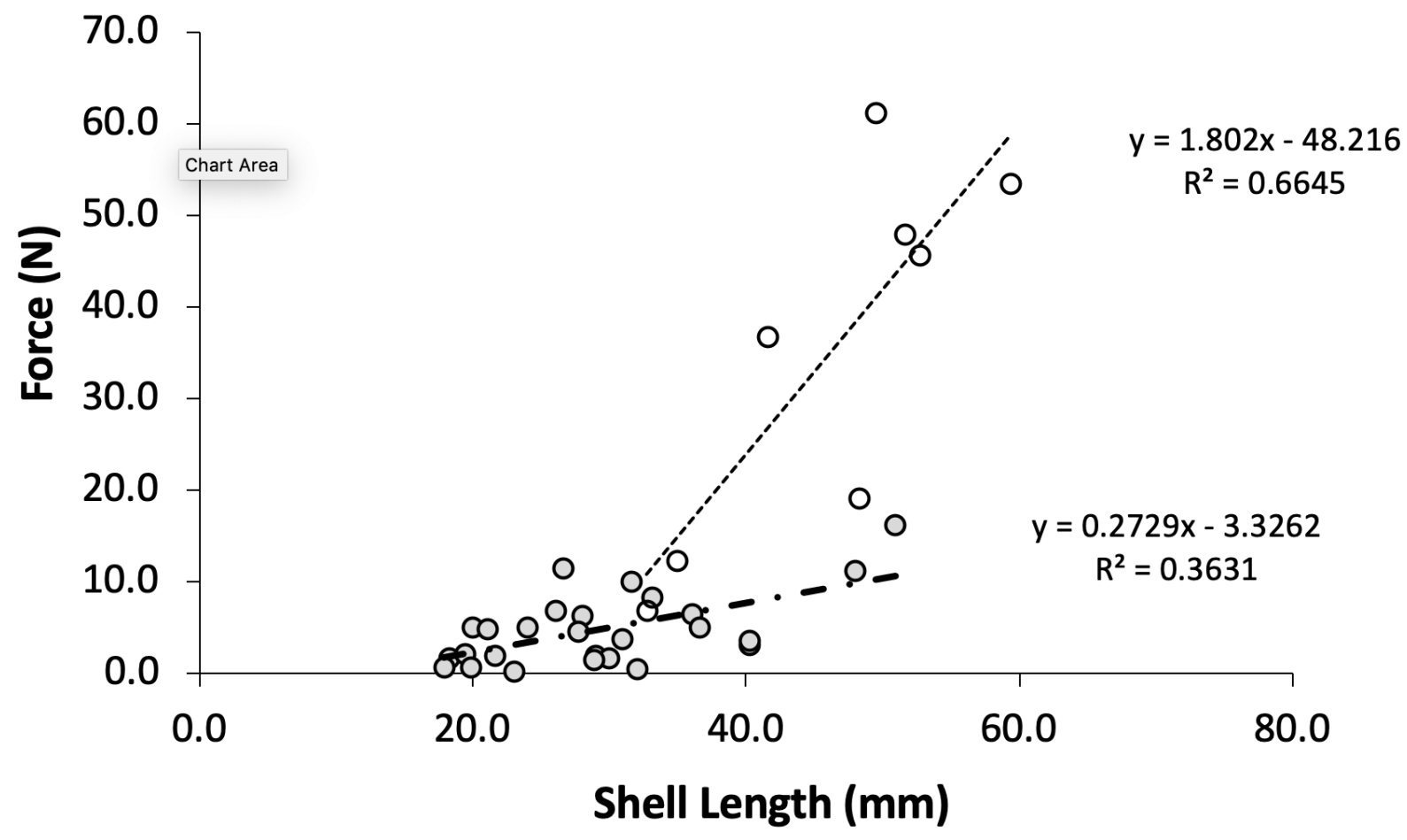

507 Fig. 4. - Resistance to shear force is greater and more sensitive to shell length in limpets that

508 continued slow foraging than in limpets that showed retreat behavior. Shear force resistance

509 (vertical axis) versus shell length (horizontal axis) for limpets engaged in either retreat behavior

510 (grey circles) or continued foraging (open circles). 


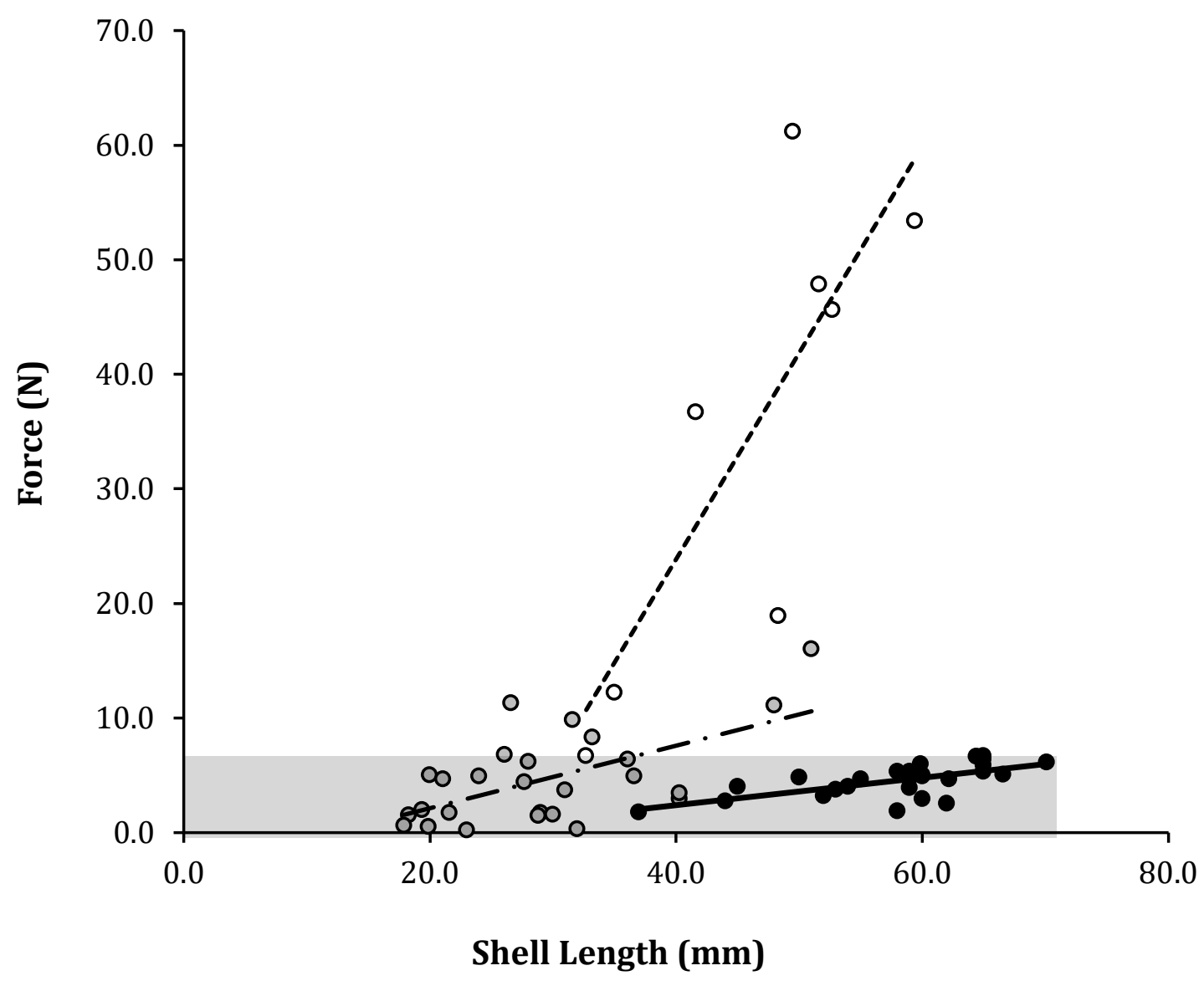

516 Fig. 5. - Maximum thrust force is greater than resistance to thrust for most retreating limpets.

517 In this figure, results from Fig. 3 are plotted with those from Fig. 4 to directly compare thrust

518 force of territorials to the resistance of moving limpets. Force to remove (grey circles retreating

519 limpets, open circles limpets that continued foraging; Fig. 4) and maximum thrust force (solid

520 circles; from Figure 3) are shown as a function of shell length. The grey area, or "danger zone"

$521(\leq 6.7 \mathrm{~N})$ represents the maximum thrust force observed, and is greater than the resistance of

522 most retreating limpets (grey circles).

523

524

525 


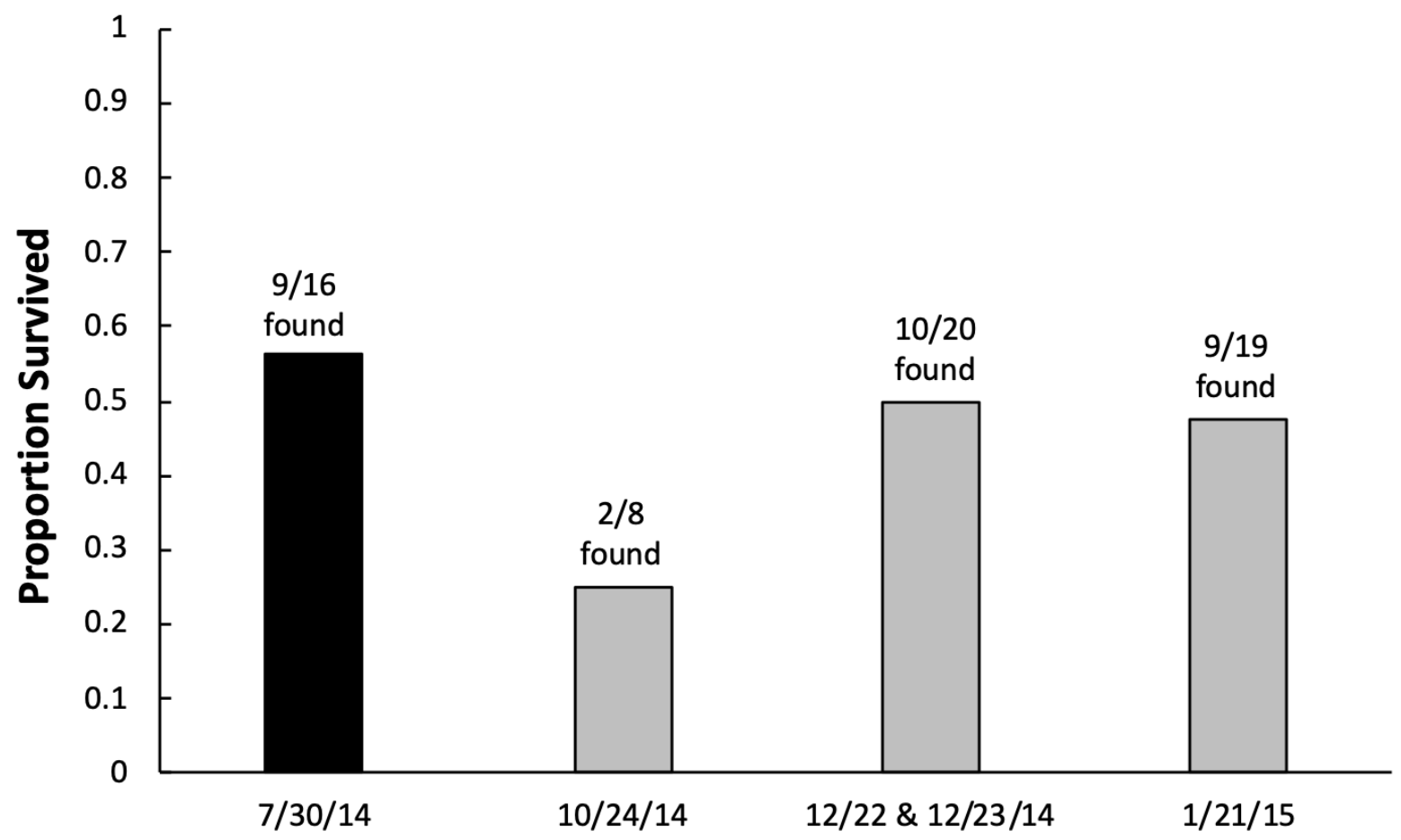

528 Fig. 6. - Survival of dislodged limpets was surprisingly high $(0.25-0.56$, average $=0.474 \pm$

5290.068 ). Number found/number dislodged shown above each bar. Dates represent when survivors

530 were found. Seven of the nine survivors from 30 July 2014 (dark bar on left) were measured on

531 that date and 5.3 months later for growth measurement (Fig. 7). 


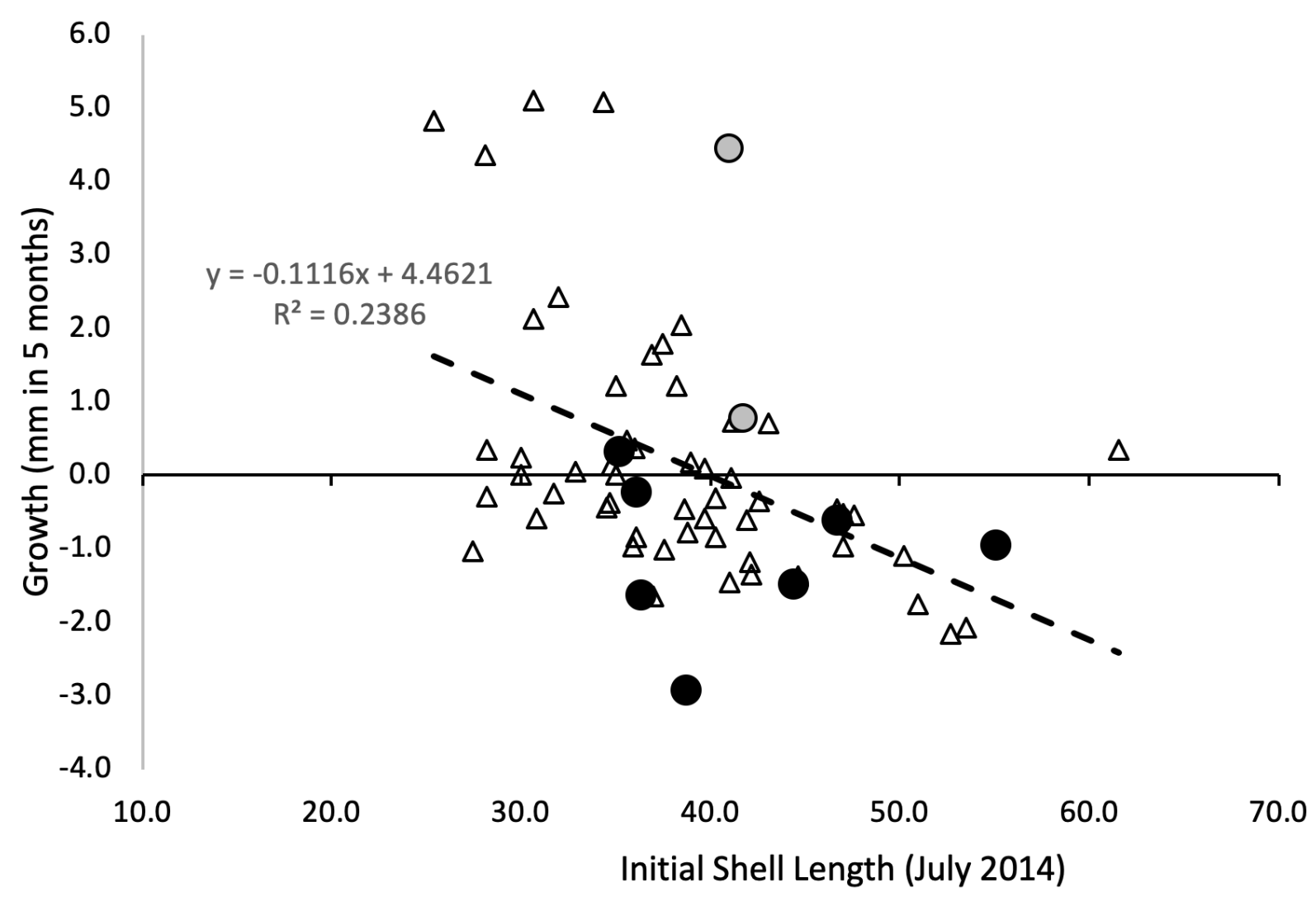

542 Fig. 7. - Growth of chasing (retreat and territorial) limpets following dislodgement (circles, $\mathrm{N}=$

543 7) was not different than that of undisturbed limpets in same habitat (triangles and dashed line, $\mathrm{N}$

$544=54)$. Scattergram shows shell length growth $(\mathrm{mm})$ from late July 2014 to early January 2015,

545 as a function of initial shell length $(\mathrm{mm})$. Regression line depicts undisturbed limpets (triangles).

546 There was no significant difference between residuals of washed-off territorials vs undisturbed

547 limpets $(P=0.37)$. 